\title{
Characterization of the Heavy-Metal-Associated Isoprenylated Plant Protein (HIPP) Gene Family from Triticeae Species
}

\author{
Heng Zhang ${ }^{1}$, Xu Zhang ${ }^{1}$, Jia Liu ${ }^{1}$, Ying Niu ${ }^{1}$, Yiming Chen ${ }^{1}$, Yongli Hao ${ }^{1}$, Jia Zhao ${ }^{1,2}$, \\ Li Sun ${ }^{1}$, Haiyan Wang ${ }^{1}$, Jin Xiao ${ }^{1, *}$ and Xiue Wang ${ }^{1, *}$ \\ 1 State Key Lab of Crop Genetics and Germplasm Enhancement, Cytogenetics Institute, \\ Nanjing Agricultural University/JCIC-MCP, Nanjing 210095, China; 2016201031@njau.edu.cn (H.Z.); \\ 2018201061@njau.edu.cn (X.Z.); 2018201063@njau.edu.cn (J.L.); 2017101125@njau.edu.cn (Y.N.); \\ 2019101119@njau.edu.cn (Y.C.); haoyongli9128@163.com (Y.H.); jiazhao@scau.edu.cn (J.Z.); \\ sunli@njau.edu.cn (L.S.); hywang@njau.edu.cn (H.W.) \\ 2 College of Agriculture, South China Agriculture University, Guangzhou 510642, China \\ * Correspondence: xiaojin@njau.edu.cn (J.X.); xiuew@njau.edu.cn (X.W.); Tel.: +86-25-84395308 (X.W.)
}

Received: 15 July 2020; Accepted: 25 August 2020; Published: 27 August 2020

\begin{abstract}
Heavy-metal-associated (HMA) isoprenylated plant proteins (HIPPs) only exist in vascular plants. They play important roles in responses to biotic/abiotic stresses, heavy-metal homeostasis, and detoxification. However, research on the distribution, diversification, and function of HIPPS in Triticeae species is limited. In this study, a total of 278 HIPPs were identified from a database from five Triticeae species, and 13 were cloned from Haynaldia villosa. These genes were classified into five groups by phylogenetic analysis. Most HIPPs had one HMA domain, while 51 from Clade I had two, and all HIPPs had good collinear relationships between species or subgenomes. In silico expression profiling revealed that 44 of the 114 wheat HIPPS were dominantly expressed in roots, 43 were upregulated under biotic stresses, and 29 were upregulated upon drought or heat treatment. Subcellular localization analysis of the cloned HIPPs from $H$. villosa showed that they were expressed on the plasma membrane. HIPP1- $V$ was upregulated in $H$. villosa after $\mathrm{Cd}$ treatment, and transgenic wheat plants overexpressing HIPP1- $V$ showed enhanced $\mathrm{Cd}$ tolerance, as shown by the recovery of seed-germination and root-growth inhibition by supplementary $\mathrm{Cd}$. This research provides a genome-wide overview of the Triticeae HIPP genes and proved that HIPP1-V positively regulates Cd tolerance in common wheat.
\end{abstract}

Keywords: HIPP; gene family; Haynaldia villosa L.; subcellular localization; Cd tolerance

\section{Introduction}

In recent decades, heavy-metal contamination in the environment has increased due to the rapid development of industry and the use of pesticides [1,2]. In some parts of the world, such as Ziyang County, China [3], soil conditions are detrimental to the growth of many or most plant species due to the increasing level of certain inorganic ions [4]. Sometimes, even low concentrations of heavy metals such as $\mathrm{Cd}, \mathrm{Pb}, \mathrm{Al}$, and $\mathrm{Hg}$ can cause great damage to plants [5-8]. Heavy metals generally produce toxic effects in plants, including chlorosis, inhibition of growth and photosynthesis, low biomass accumulation, imbalance of nutrient assimilation and water, and senescence, which eventually lead to plant death [9]. Cd is a nonessential heavy metal and is ranked among the top 20 toxins [10], and it can affect many processes of plant growth and development. Contamination of soil with $5 \mu \mathrm{M}$ Cd can significantly affect the seed germination and seedling growth of barley [11]. Different concentrations of $\mathrm{Cd}$ can also affect the root growth of wheat and rice [12,13]. Photosynthetic indices 
of tomato seedlings, such as the photosynthetic rate $(\mathrm{Pn})$ and the intracellular $\mathrm{CO}_{2}$ concentration $(\mathrm{Ci})$, can be severely affected under Cd stress [14]. In order to survive in environments containing heavy metals, plants have to develop a range of strategies to cope with these heavy metals [9]. Research reports that several protein families are involved in the detoxification and sequestration of heavy metals, such as ATP-binding cassette (ABC) transporters [15], zinc/iron-regulated transporter proteins (ZIPs) [16], heavy-metal ATPases (HMAs) [17-19], cation diffusion facilitators (CDFs) [20], natural resistance-associated macrophage proteins (Nramps) [21], and heavy-metal-associated isoprenylated plant proteins (HIPPs) [22].

HIPPs are a group of metal-binding metallochaperones characterized by a heavy-metal-associated (HMA) domain and an isoprenylation motif [23]. Although the HMA domain and the isoprenylation motif commonly occur in many organisms, from bacteria to humans, the presence of both interacting in the same protein has been observed only in vascular plants [24]. Analysis of HIPP-family genes has mainly been done for Oryza and Arabidopsis, with a few studies in other species [23,24]. Thus far, 45 HIPP genes have been identified in Arabidopsis, 59 in Oryza, 74 in Populus trichocarpa, 52 in Setaria italic, and 5 in Selaginella moellendorffii, and these genes have been divided into five distinct clusters [23]. All HIPP proteins have a conserved structure, including an HMA domain and a C-terminal isoprenylation CaaX motif (where " $\mathrm{C}$ " is cysteine, "a" is an aliphatic amino acid, and " $\mathrm{X}$ " is any amino acid); some of them also contain other domains, such as glycine-rich repetitions and a proline-rich motif [23].

The functions of HIPPs have been extensively studied in Arabidopsis [25], Oryza [26], tomato [27], barley [28], wheat [29], etc., and HIPPs have been revealed to play an important role in the maintenance of heavy-metal homeostasis and detoxification. In Arabidopsis, the expression of AtCdI19 can be induced by $\mathrm{Cd}, \mathrm{Hg}, \mathrm{Fe}$, and $\mathrm{Cu}$, and overexpression of $\mathrm{CdI} 19$ confers $\mathrm{Cd}$ tolerance in transgenic Arabidopsis [30]. Expression of Arabidopsis HIPP20, HIPP22, HIPP26, and HIPP27 in yeast confers increased Cd resistance to the Cd-sensitive yeast strain ycf1. The hipp20/21/22 triple mutant is more sensitive to $\mathrm{Cd}$ and shows significantly decreased shoot fresh weight compared to the wild-type [24]. $A t F P 6$ expression can be induced by $\mathrm{Cd}$ and $\mathrm{Zn}$ and the protein can bind $\mathrm{Pb}, \mathrm{Cd}$, and $\mathrm{Cu}$; overexpression of AtFP6 can enhance tolerance to Cd compared to the wild-type [22]. AtHIPP44 can interact with the transcription factor MYB49, thus leading to its upregulated expression and the subsequent reduction of $\mathrm{Cd}$ accumulation [31]. In rice, the expression of OsHIPP16, OsHIPP28, OsHIPP34, OsATX1, and OsHIPP60 in roots and shoots can be induced by $\mathrm{Mn}, \mathrm{Cd}$, and $\mathrm{Cu}$ [26]. The expression of OsHIPP34, OsHIPP60, and OsHIPP16 in a yeast mutant showed that OsHIPP34 can increase resistance to Cu, OsHIPP60 can increase resistance to $\mathrm{Zn}$, and OsHIPP16 can increase resistance to $\mathrm{Cd}$ and $\mathrm{Zn} \mathrm{[26].}$ Additionally, the oshipp 42 mutant grows more weakly than the wild-type under $\mathrm{Cu}, \mathrm{Zn}, \mathrm{Cd}$, and $\mathrm{Mn}$ stresses [26]. OsHIPP29 is upregulated by high $\mathrm{Cd}$ and $\mathrm{Zn}$ concentrations in the shoots and roots; the mutants and RNAi lines of OsHIPP29 show decreased plant heights and dry biomass compared to the wild-type under $\mathrm{Cd}$ exposure [32]. Some HIPP genes may also be involved in other abiotic-stress responses. HvFP1 from barley shows a complex expression pattern with induction under different abiotic stress conditions (e.g., cold, drought, and heavy-metal exposure) during leaf senescence and in response to abscisic acid [28]. Like HvFP1, HIPP26 from Arabidopsis can also be induced by cold, salt, and drought stresses [33]. Evidence has accumulated for the critical role of HIPP in response to biotic stresses. In Arabidopsis, AtHIPP3 acts as an upstream regulator of the salicylate-dependent pathway of pathogen response [25]. HIPP27 is a host-susceptibility factor required for beet cyst nematode infection and development [34]. In tobacco, NbHIPP26 interacts with TGB1 (the potato mop-top virus movement protein) to activate the drought-stress response and to facilitate the long-distance movement of the virus [35]. In wheat, transient silencing of TaHIPP1 enhances stripe-rust resistance, indicating that TaHIPP1 acts as a negative regulator [36].

Common wheat (Triticum aestivum L.) is one of the most important food crops around the world, and the growth and yield of wheat are affected by various environmental factors, such as heavy metals [37]. To date, some genes related to heavy metal tolerance have been reported in wheat, including TaVP1 [38], TaGolS3 [37], TaEXPA2 [39], TaHMA2 [40], TaPCS1 [41], TaCNR2 [42], and TaPCS1 [43]. 
In this study, genome-wide identification of the HIPP gene family in Triticeae species was performed by searching the published sequences. A phylogenetic tree of the HIPP genes was constructed and the evolutionary relationships were analyzed. Chromosome distribution and protein structure were further studied to gain a better understanding of HIPP genes in wheat. The potential functions of the common wheat HIPP genes were predicted through their expression profiles based on in silico analysis. Haynaldia villosa L. $(2 n=2 x=14, \mathrm{VV})$ is a diploid wild relative of wheat. Previous studies have shown that $H$. villosa is resistant to various wheat diseases such as stripe rust and powdery mildew, and also possesses the characteristics of resistance to drought, cold, and salt; therefore, it provides excellent material for wheat genetic improvement [44-46]. As $H$. villosa has not been sequenced, we cloned $H$. villosa's HIPPs through homology-based cloning. One of the HIPP genes, HIPP1-V, was transformed into wheat to study its role in $\mathrm{Cd}$ tolerance. Our results will support the understanding of the evolution and diversification of HIPPs in Triticeae species at a genome-wide scale.

\section{Results}

\subsection{Genome-Wide Identification, Phylogenetic Analysis, and Protein Structure Analysis of the HIPP Gene} Family in Triticeae Species

In total, 278 HIPP genes from five Triticeae species were identified from the public database. Of these, 114 were from common wheat (T. aestivum), 33 from Triticum urartu, 40 from Aegilops tauschii, 58 from Triticum dicoccoides, and 33 from Hordeum vulgare. By using the homology cloning technique, 13 HIPPs from H. villosa were cloned (Figure 1). To understand the phylogeny of HIPP genes, the evolutionary relationships of the above 291 Triticeae HIPPS ( 278 from five Triticeae species and 13 from $H$. villosa), along with 40 from Brachypodium distachyon, 59 from rice, and 45 from Arabidopsis, were phylogenetically analyzed and a neighbor-joining tree was built (Figure 2 and Supplementary Table S1). The HIPPS were divided into five clades (Clades I-V) according to the classification established for Arabidopsis. Clade IV was the smallest clade with 11 members, while Clade II was the largest with 128 members. Apart from H. villosa, the other analyzed Triticeae species possessed genes in each of these clusters. In the same clade, HIPP genes from different Triticeae species were clustered together, and HIPP genes from the same species also tended to aggregate (Figure 2), showing differences between the HIPP genes of different species and the conservation of HIPP genes within the same species.

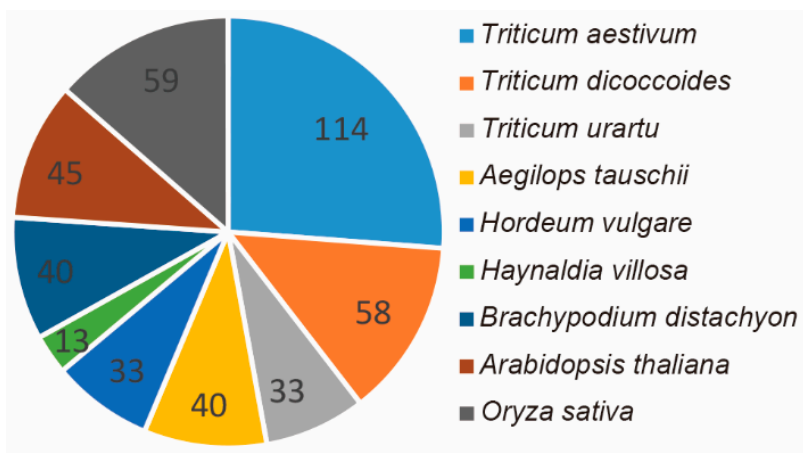

Figure 1. The total number of heavy-metal-associated isoprenylated plant protein $(H I P P)$ genes in the nine species of T. aestivum, T. dicoccoides, T. urartu, Ae. tauschii, H. vulgare, H. villosa, B. distachyon, A. thaliana, and Oryza sativa.

The conserved domains of the HIPP proteins were evaluated using the Conserved Domain Database. All HIPP proteins contained 1 or 2 HMA domains (pfam00403) and a C-terminal isoprenylation CaaX motif (Supplementary Figure S1). Significant differences in the genes' functional domains were observed between different clades (Supplementary Figure S1); for example, the 51 HIPPs in Clade I had two HMA domains and the others all had one. Members of the same clade resembled 
one another, e.g., the eight genes in Clade IV were similar in size, ranging from 139 to 175 amino acids (aa), and they all had an HMA domain and an isoprenylation motif (Supplementary Figure S1d). Minor differences within the same clades were observed, e.g., the sizes and functional domains of Clade V were more diversified; the coding sequence (CDS) lengths of the members of this clade ranged from 77 to 1089 aa and some genes also contained other functional domains, e.g., a copA superfamily domain was found in TaHIPP7-A, TdHIPP7-A, and TuHIPP7; TaHIPP46-A contained an NB-ARC superfamily domain (Supplementary Figure S1e), etc.

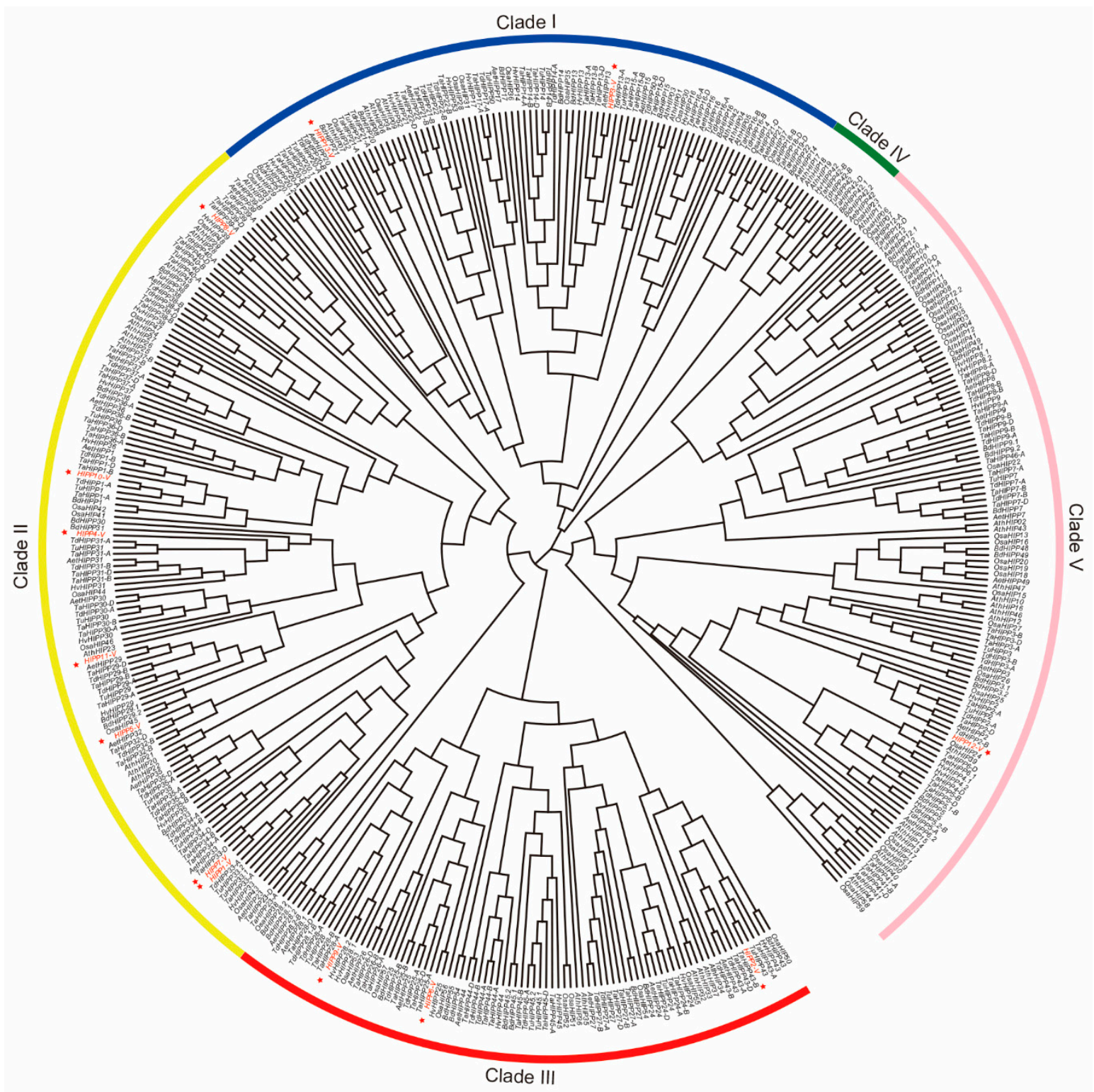

Figure 2. The phylogenetic analysis of the HIPP gene family from nine plant species. Species abbreviations: Ta: T. aestivum; Tu: T. urartu; Aet: Ae. tauschii; Td: T. dicoccoides; Hv: H. vulgare; Bd: B. distachyon; Ath: A. thaliana; Osa: O. sativa; -V: H. villosa. The red asterisks indicate the HIPP genes from H. villosa.

\subsection{Chromosomal Distribution of HIPPs}

Based on the genome databases data for common wheat, T. dicoccoides, T. urartu, Ae. tauschii, and H. vulgare, the chromosome constitution of the HIPP family was investigated (Figure 3 and Table 1). The HIPPS were distributed on all of the chromosomes of the diploid genomes and polyploid subgenomes, indicating that the HIPP genes were distributed on the chromosomes of each homologous 
group. However, the number of HIPP genes of different homeologous groups varied greatly, with a minimum of 1-3 (the sixth and seventh homoeologous groups) and a maximum of 8-11 (the second homoeologous group) (Table 1). For homoeologous chromosomes from different genomes of wheat and its ancestral/related species, most of the corresponding HIPP orthologs were present in the syntenic genome regions. For example, HIPP1, HIPP7, HIPP16, HIPP20, HIPP27, and HIPP29 were on the homoeologous Group 2 chromosomes in Triticeae species, while HIPP37 and HIPP39 were on the Group 3 chromosomes (Figure 3a-d). However, there were some exceptions; for example, HIPP4 and HIPP6 were present on Chromosome 2D, but not on Chromosome 2A or 2D in T. aestivum (Figure 3a). Furthermore, HIPP21, HIPP30, and HIPP12 were on 4AL of T. aestivum and T. dicoccoides (Figure 3a,b), but on $4 \mathrm{AS}$ of T. urartu (Figure 3d), indicating that Chromosome 4A of tetraploid and hexaploid experienced structural rearrangement during its evolution. The HIPP genes of the other chromosomes were potential orthologs that showed a good collinearity (Figure 3).

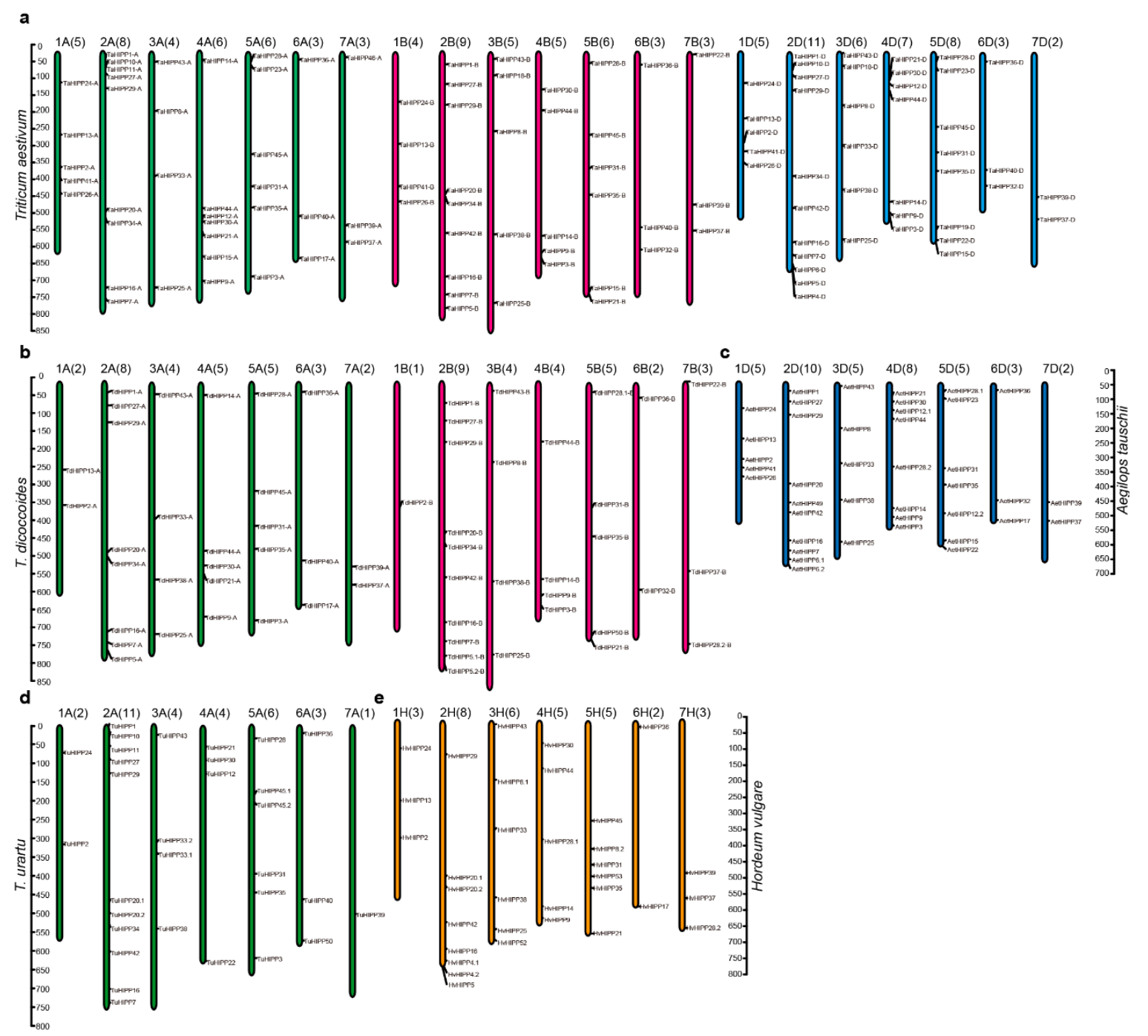

Figure 3. Chromosomal distribution of the HIPPs in the five Triticeae species. The chromosomal distribution of the HIPP genes in T. aestivum (a), T. dicoccoides (b), Ae. tauschii (c), T. urartu (d), and H. vulgare (e). The identities of the chromosomes are indicated at the top of each chromosome- the number in brackets corresponds to the number of genes located on the corresponding chromosome, while the HIPP gene names are shown to the right of each chromosome. Ta: T. aestivum; Tu: T. urartu; Aet: Ae. tauschii; Td: T. dicoccoides; Hv: H. vulgare. 
Table 1. Number of HIPPs from different species on each of the chromosomes.

\begin{tabular}{|c|c|c|c|c|c|c|c|c|c|}
\hline \multirow{2}{*}{ Chromosome } & \multicolumn{3}{|c|}{ T. aestivum } & \multicolumn{2}{|c|}{ T. dicoccoides } & \multirow{2}{*}{$\frac{\text { T. urartu }}{\mathrm{A}}$} & \multirow{2}{*}{$\frac{\text { Ae. tauschii }}{\text { D }}$} & \multirow{2}{*}{$\begin{array}{c}\text { H. vulgare } \\
\mathbf{H}\end{array}$} & \multirow{2}{*}{ Total } \\
\hline & $\mathbf{A}$ & B & D & $\mathbf{A}$ & B & & & & \\
\hline 1 & 5 & 4 & 5 & 2 & 1 & 2 & 5 & 3 & 27 \\
\hline 2 & 9 & 9 & 11 & 8 & 10 & 11 & 10 & 8 & 76 \\
\hline 3 & 4 & 5 & 6 & 4 & 4 & 4 & 5 & 6 & 38 \\
\hline 4 & 7 & 5 & 7 & 5 & 4 & 4 & 8 & 5 & 45 \\
\hline 5 & 6 & 6 & 8 & 5 & 5 & 6 & 7 & 5 & 48 \\
\hline 6 & 3 & 3 & 3 & 3 & 2 & 3 & 3 & 3 & 23 \\
\hline 7 & 3 & 3 & 2 & 2 & 3 & 1 & 2 & 3 & 19 \\
\hline Unknown * & & & & & & 2 & & & 2 \\
\hline Total & 37 & 35 & 42 & 29 & 29 & 33 & 40 & 33 & 278 \\
\hline
\end{tabular}

Comparing the A genomes of common wheat, T. dicoccoides, and T. urartu, four HIPPs were found on Chromosome 3A and three on Chromosome 6A in all three species (Table 1). However, there were differences on the other chromosomes, especially in the number of HIPPs on Chromosome 1A-five in common wheat, two in T. dicoccoides, and two in T. urartu. One possible reason for this is that HIPP has replicated and formed gene clusters over the course of the evolution of common wheat (Table 1). Moreover, the number of HIPP genes found on Chromosome 4A was also very different between the three species, with seven in common wheat, five in T. dicoccoides, and four in T. urartu (Table 1). Comparing the B subgenomes of common wheat and T. dicoccoides, it was found that except for Chromosome 7B (three HIPPs), the number of HIPPs was different on the other chromosomes, of which $1 \mathrm{~B}$ had the largest difference, with four in common wheat and one in T. dicoccoides, and the number of HIPP genes on the remaining chromosomes differed by one (Table 1). Comparing the $\mathrm{D}$ genomes of common wheat and Ae. tauschii, the total number of HIPP genes was 42 and 40, respectively. The numbers of genes on Chromosomes 1D, 6D, and 7D were the same, with five, three, and two, respectively. There was one more HIPP gene on Chromosomes 2D, 3D, and 5D in common wheat than in Ae. tauschii, and one less HIPP gene on Chromosome 4D in common wheat than in Ae. tauschii. This shows that the number of HIPP genes in the D genome has been relatively stable over the course of its evolution (Table 1).

\subsection{The Expression Pattern of the HIPP Gene Family in Common Wheat}

To predict the potential functions of the identified HIPPs, we investigated their expression in different tissues or in responses to various biotic and abiotic stresses through in silico expression profiling. The expression patterns of wheat HIPPs in different tissues (e.g., roots, leaves, spikes, and grains) under two biotic stresses (e.g., stripe-rust pathogen CYR31 and powdery-mildew pathogen E09) and two abiotic stresses (e.g., drought and heat) were investigated using the wheat RNA-seq data from publicly available databases. The expression level was measured as tags per million (TPM), and the Z-score-normalized values of the TPM were used to generate a heat map in R Studio (Figure 4). Tissue-specific expression analysis showed that 44 genes had the highest expression levels in the roots (e.g., TaHIPP43-A), 23 genes in the leaves (e.g., TaHIPP2-A), 42 genes in the spikes (e.g., TaHIPP29-B), and only TaHIPP20-A, TaHIPP20-B, TaHIPP21-A, TaHIPP21-D, and TaHIPP36-B in the grains (Figure 4a). Most HIPP genes showed the highest expression levels in the roots and the lowest in the grains, and the numbers of HIPP genes highly expressed in the spikes and leaves were somewhere in between. Different genes showed various expression patterns under biotic (e.g., Bgt and Pst) and abiotic (e.g., drought and heat) stresses. In response to Bgt and Pst infection, 52 and 69 genes were significantly upregulated, 31 and 13 genes were significantly downregulated, and 31 and 32 genes remained unchanged, respectively (Figure $4 b, c)$. In response to drought and heat induction, 44 and 40 genes were significantly upregulated, 22 and 31 genes were significantly downregulated, and 48 and 43 genes remained unchanged, respectively (Figure $4 \mathrm{~d}$,e). When infected 
by $B g t$ and $P s t, 41$ genes (e.g., TaHIPP13-B) were upregulated (Supplementary Figure S2a), six genes (e.g., TaHIPP36-D) were downregulated (Supplementary Figure S2b), and 28 genes (e.g., TaHIPP36-B) showed no obvious expression change (Supplementary Figure S2c). Under drought and heat stresses, 29 genes (e.g., TaHIPP35-D) were upregulated (Supplementary Figure S2d), 15 genes (e.g., TaHIPP24-B) were downregulated (Supplementary Figure S2e), and 40 genes (e.g., TaHIPP10-A) showed no obvious expression change (Supplementary Figure S2f). When combining the four kinds of stresses, 14 genes (e.g., TaHIPP35-A) were upregulated (Supplementary Figure S2g) and none were downregulated (Supplementary Figure S2h).

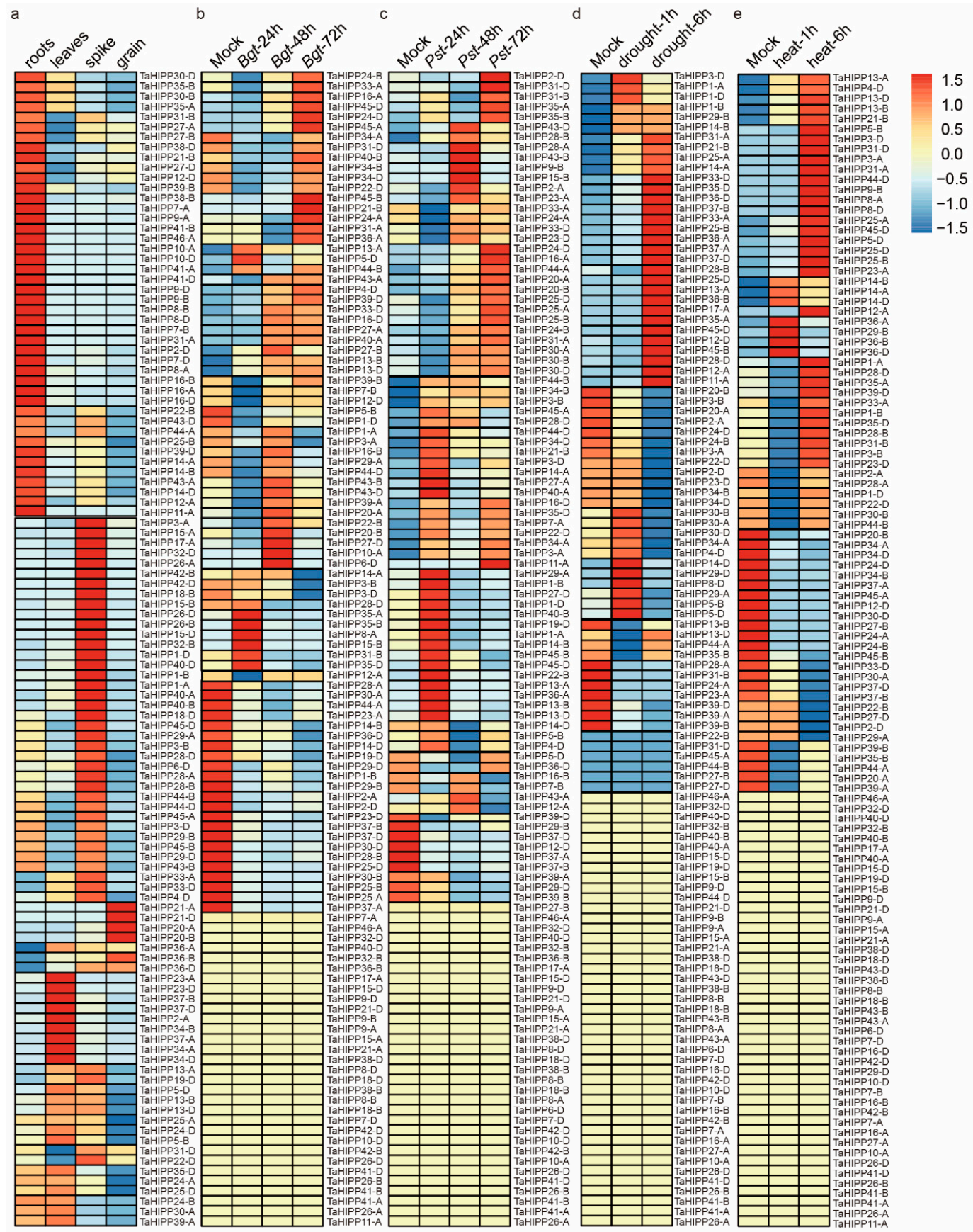

Figure 4. Heat map of the expression profiling of common wheat HIPPs in different tissues and under various stresses: the expression of HIPPs in different tissues (a), and their response to powdery mildew (b), yellow rust (c), drought (d), and heat treatment (e). The expression signal of each gene was based on the Z-score-normalization value. Abbreviations: Bgt: powdery mildew; Pst: yellow rust. 


\subsection{Cloning and Subcellular Localization Analysis of the HIPPs from H. villosa}

The 13 cloned HIPPs from $H$. villosa were assigned the names HIPP1- $V$ to HIPP13- $V$, which were classified into four clades. HIPP7- $V$, which encodes a protein of 151 aa, had the shortest CDS length, e.g., 456 bp. The longest one was HIPP2- $V$ at $1251 \mathrm{bp}$, which encodes 416 aa. The predicted isoelectric points of the HIPPs-V ranged from 5.21 (HIPP13-V) to 10.04 (HIPP10-V) (Table 2).

Table 2. Information of the HIPP gene family in H. villosa.

\begin{tabular}{cccccccc}
\hline Name & $\begin{array}{c}\text { Homologs in } \\
\text { H. vulgare }\end{array}$ & ORF & aa & $\begin{array}{c}\text { Location of HMA } \\
\text { Domain (aa) }\end{array}$ & $\begin{array}{c}\text { No. of HMA } \\
\text { Domain }\end{array}$ & PI & MW (kDa) \\
\hline HIPP1- $V$ & HvHIPP33 & 456 & 151 & $37-91$ & 1 & 9.61 & 16.63 \\
HIPP2- $V$ & HvHIPP43 & 1251 & 416 & $16-63$ & 1 & 7.54 & 44.21 \\
HIPP3-V & HvHIPP13 & 1023 & 340 & $22-76,162-204$ & 2 & 9.63 & 36.24 \\
HIPP4- $V$ & HvHIPP31 & 486 & 161 & $35-94$ & 1 & 10.01 & 17.81 \\
HIPP5- $V$ & HvHIPP31 & 489 & 162 & $36-95$ & 1 & 10.3 & 17.64 \\
HIPP6-V & HvHIPP25 & 999 & 332 & $12-73$ & 1 & 5.62 & 36.36 \\
HIPP7-V & HvHIPP33 & 456 & 151 & $37-91$ & 1 & 9.78 & 16.59 \\
HIPP8-V & HvHIPP39 & 507 & 168 & $10-61$ & 1 & 8.41 & 18.72 \\
HIPP9-V & HvHIPP28.1 & 921 & 306 & $12-59$ & 1 & 4.86 & 33.35 \\
HIPP10- $V$ & HvHIPP36 & 468 & 155 & $35-90$ & 1 & 10.04 & 17.35 \\
HIPP11-V & HvHIPP29 & 489 & 162 & $39-98$ & 1 & 9.97 & 17.64 \\
HIPP12- $V$ & HvHIPP2 & 498 & 165 & $11-60$ & 1 & 6.79 & 17.92 \\
HIPP13- $V$ & HvHIPP20.2 & 1065 & 354 & $71-122,167-227$ & 2 & 5.21 & 39.23 \\
\hline
\end{tabular}

Note: ORF: open reading frame; aa: amino acids; HMA: heavy-metal-associated; PI: isoelectric point; MW: molecular weight.

Investigating the subcellular localization of a protein provides clues towards the elucidation of its function. To verify where the HIPPs-V proteins were localized in vivo, GFP (green fluorescent protein)-tagged fusion proteins were expressed and observed in the leaves of Nicotiana Benthamiana via transient expression using the Agrobacterium method. The GFP signal of the fusion proteins could be detected for all 13 cloned HIPP-V proteins, with different localization signals (Figure 5). Compared to the control, which had an even distribution of GFP fluorescence (Figure 5a), all HIPP-V proteins were localized on the plasma membrane (PM), but with different fluorescence intensities, e.g., the fluorescence intensities of HIPP2, $-4,-5,-7,-9$, and -11-V were weaker than those of the others (Figure $5 c, e, f, h, j, l)$. Some HIPPs also had obvious signals in the cytoplasm, such as HIPP2-V and HIPP9-V (Figure 5c,j). These different subcellular localizations revealed that they may be involved in multiple biological processes and may have distinct functions. 

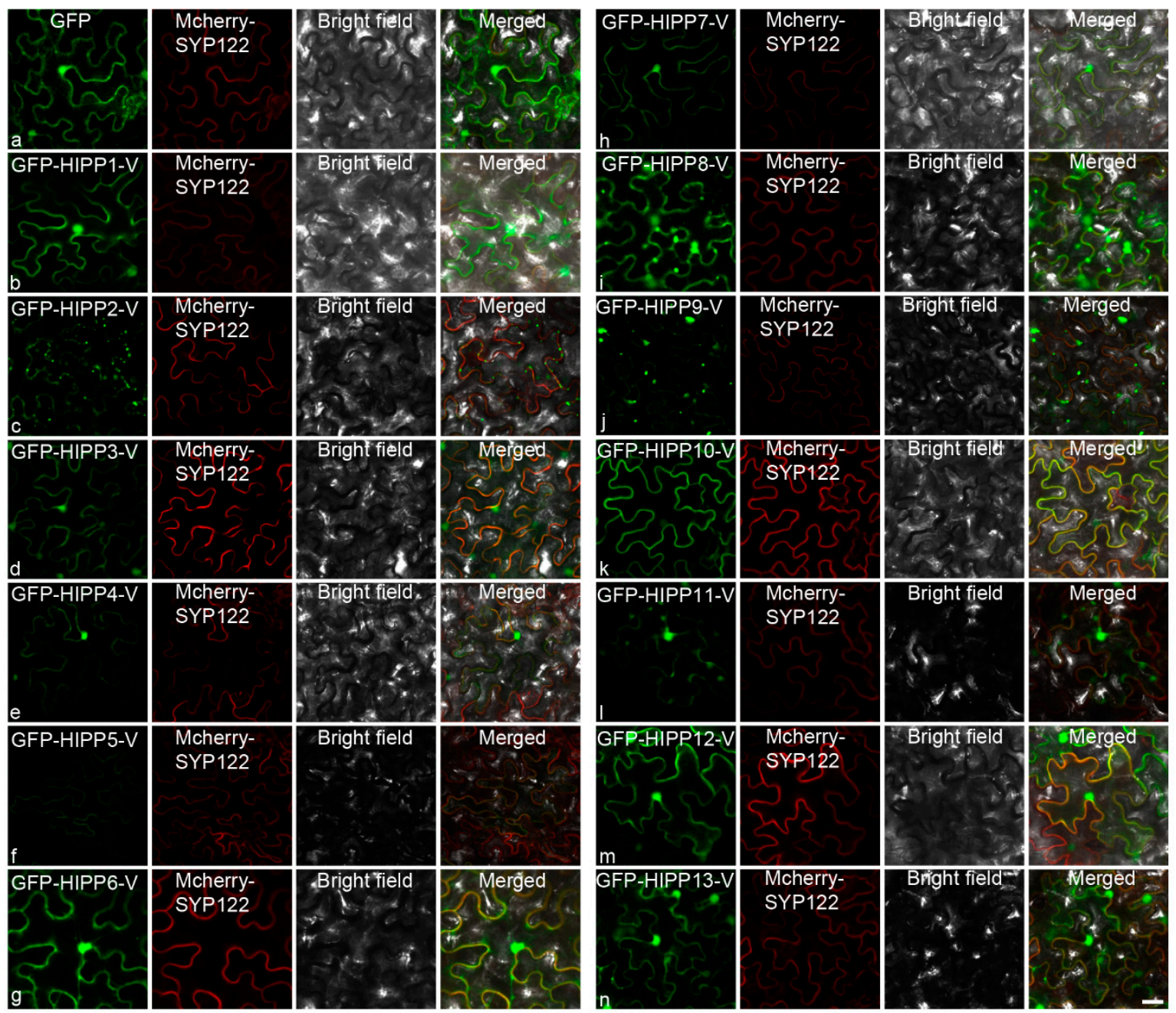

Figure 5. Subcellular localization of HIPPs in the epidermal cells of Nicotiana benthamiana: subcellular localization of GFP (a), GFP-HIPP1-V (b), GFP-HIPP2-V (c), GFP-HIPP3-V (d), GFP-HIPP4-V (e), GFP-HIPP5-V (f), GFP-HIPP6-V (g), GFP-HIPP7-V (h), GFP-HIPP8-V (i), GFP-HIPP9-V (j), GFP-HIPP10-V (k), GFP-HIPP11-V (1), GFP-HIPP12-V (m), and GFP-HIPP13-V (n). GFP was used as the control. The localization of mCherry-SYP122 is shown in red, and the localization of GFP and its fusion proteins are shown in green. Scale bar $=10 \mu \mathrm{m}$.

\subsection{HIPP1-V Positively Regulates Cd Tolerance in Common Wheat}

Previous studies have demonstrated the involvement of HIPPs in cadmium (Cd) homeostasis. Quantitative reverse-transcription PCR (qRT-PCR) analysis was used to investigate HIPP1-V expression in response to $\mathrm{Cd}$. Following the treatment of $H$. villosa at the two-leaf stage with $1 \mathrm{mM} \mathrm{Cd}^{2+}, H I P P 1-V$ expression in the roots rapidly increased $1 \mathrm{~h}$ after inoculation (hai), reached a peak level at $12 \mathrm{hai}$, and remained at a higher level from 24 hai (Figure 6a). In the stems, HIPP1-V expression increased at 2 hai, declined at 6 hai, increased at 12 hai, and remained at a high level for all of the tested time points (Figure 6b). In the leaves, HIPP1- $V$ expression increased at 2 hai, reached a peak level at 12 hai, and declined at 24 hai (Figure 6c). These results showed that HIPP1-V was upregulated after $\mathrm{Cd}$ induction. Although the expression trend was different in different tissues of $H$. villosa, they were all upregulated. 

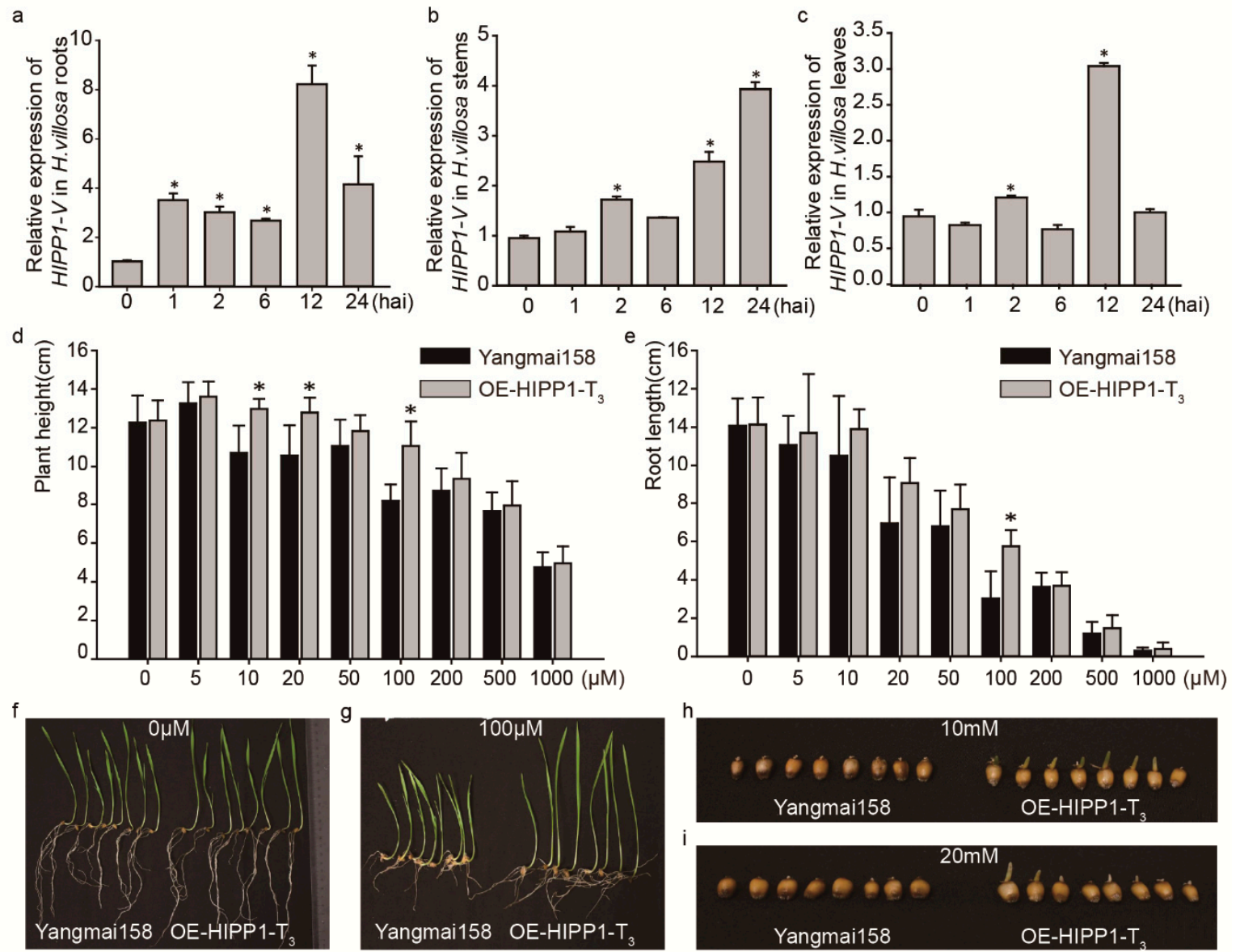

Figure 6. Tolerance of HIPP1- $V$ transgenic plants to Cd. Time-course expression profiling of HIPP1- $V$ of $H$. villosa in response to Cd treatment in the roots (a), stems (b), and leaves (c). (d) The plant height between OE-HIPP1- $\mathrm{T}_{3}$ and Yangmai158 plants exposed to different $\mathrm{Cd}$ concentrations. (e) The root length between OE-HIPP1- $\mathrm{T}_{3}$ and Yangmai158 plants in different $\mathrm{Cd}$ concentrations. (f-i) OE-HIPP1- $\mathrm{T}_{3}$ and Yangmai158 phenotypes under treatments of different Cd concentrations $(0,100 \mu \mathrm{M}, 10 \mathrm{mM}$, and $20 \mathrm{mM}) .{ }^{*} p<0.05$. hai: hours after induction.

The function of HIPP1- $V$ in $C d$ tolerance was validated using stable transformation. The expression vector pBI220: HIPP1-V was constructed by cloning the HIPP1- $V$ gene into $\mathrm{pBI} 220$ driven by the $2 \times 35$ S promoter. The vectors pBI220: HIPP1-V and pAHC20 (carrying a Bar gene as a selection marker) were co-transformed into Yangmai158 via particle bombardment, and five positive transgenic plants were obtained (Supplementary Figure S3). OE-HIPP1-T $\mathrm{T}_{0}-17-3$ and OE-HIPP1-T 0 -27-3 were selected for further analysis due to their higher HIPP1- $V$ expression levels (Supplementary Figure $\mathrm{S} 3 \mathrm{~b}$ ). Their derived $\mathrm{T}_{3}$ lines, OE-HIPP1- $\mathrm{T}_{3}-1$ and $\mathrm{OE}-\mathrm{HIPP} 1-\mathrm{T}_{3}-2$, were identified as positive lines and used for $\mathrm{Cd}$ treatment. When treated with $0 \mu \mathrm{M} \mathrm{Cd}$, there were no differences in plant height and root length between receptor Yangmai158 and OE-HIPP1- $\mathrm{T}_{3}$ (Figure 6d-f). As the concentration of Cd increased, the root length and plant height of both plants gradually decreased, but the decrease was more pronounced in Yangmai158 plants (Figure 6d,e). When the concentration of Cd reached $100 \mu \mathrm{M}$, the differences in root length and plant height were the greatest; Yangmai158 and OE-HIPP1-V-T were $8.19 \mathrm{~cm}$ and $11.06 \mathrm{~cm}$ in height (Figure $6 \mathrm{~d}, \mathrm{~g}$ ) and $3.03 \mathrm{~cm}$ and $5.75 \mathrm{~cm}$ in root length, respectively (Figure $6 \mathrm{e}, \mathrm{g}$ ). As the concentration of $\mathrm{Cd}$ continued to increase, the growth status of Yangmai158 and OE-HIPP1-V-T 3 tended to be consistent (Figure $6 \mathrm{~d}, \mathrm{e}$ ). When the concentrations of Cd reached $10 \mathrm{mM}$ and $20 \mathrm{mM}$, the seeds of OE-HIPP1-V-T 3 were still able to germinate, but the germination of Yangmai158 was completely suppressed (Figure $6 \mathrm{~h}, \mathrm{i}$ ). These results indicate that HIPP1-V could significantly improve the tolerance of common wheat to $\mathrm{Cd}$. 


\section{Discussion}

\subsection{The Cd Tolerance of HIPP1-V Could Expand Wheat Breeding Resources}

Wheat is an important crop worldwide and is known to be a leading dietary source of Cd [47]. Improving wheat tolerance to $\mathrm{Cd}$ and reducing $\mathrm{Cd}$ accumulation in grains are issues that need to be addressed in current wheat breeding. Some Cd-tolerance-related genes in wheat have been reported; including HMA-containing genes [29]. This HMA domain has a highly conserved CysXXCys (X refers to any amino acid) motif comprising a beta-alpha-beta-alpha fold shape for binding heavy metals, such as $\mathrm{Cd}, \mathrm{Cu}$, or $\mathrm{Zn}$ [48]. There have been two types of HMA-domain-containing proteins found in plants to date, namely HPPs (HMA plant proteins) and HIPPs (HMA isoprenylated plant proteins), which are a group of metal-binding metallochaperones $[23,26]$. These proteins play crucial roles in metal homeostasis and detoxification in plants. The wheat heavy-metal ATPase 2 (TaHMA2) can transport $\mathrm{Zn}^{2+}$ and $\mathrm{Cd}^{2+}$ across membranes, and overexpression of TaHMA2 in Arabidopsis increases the root length and fresh weight and enhances $\mathrm{Zn}^{2+} / \mathrm{Cd}^{2+}$ root-to-shoot translocation compared to that of the wild-type $[40,49]$. TaHIPP1 from common wheat contains an HMA domain, and overexpression of TaHIPP1 in yeast significantly increases the cell growth rate under $\mathrm{Cu}^{2+}$ stress [29]. The cell number regulator 2 (TaCNR2) from common wheat is also involved in regulating heavy-metal translocation; the expression of TaCNR2 in wheat seedlings increases under $\mathrm{Cd}$, Zn, and Mn treatments, and overexpression of TaCNR2 in Arabidopsis and rice plants enhances their tolerances to Cd, Zn, and Mn stresses. Using new gene resources from alien species is a very useful approach for breeding new cultivars [50]. In this study, HIPP1-V, which contains an HMA domain, was upregulated in the roots, stems, and leaves of $H$. villosa, induced by $\mathrm{Cd}$. The overexpression of HIPP1-V was able to increase the tolerance of common wheat to $\mathrm{Cd}$. This result indicates that HIPP1- $V$ may represent a gene resource for improving wheat tolerance to $\mathrm{Cd}$ stress.

\subsection{Identification and Characterization of the HIPP Gene Family Can Help to Better Understand the Evolutionary Relationships in Triticeae Species}

HIPP proteins contain an HMA domain and a conserved isoprenylated motif, and are found only in vascular plants [23,51]. HIPP-family genes have been reported mostly in Arabidopsis and rice $[23,26]$. de Abreu-Neto speculated that plant metallochaperone genes (including ATX, HPP, and $H I P P)$ share a common ancestor in plants and algae species, and started diversification early in plant evolution [23]. The distribution of the HIPP genes on chromosomes and segmental duplication events highlight the HIPP family's expansion in the rice genome [26]; such gene duplication during evolution can help plants adapt to various environmental stresses [52]. In this study, a total of 291 HIPP genes were identified from five Triticeae species and H. villosa, and the HIPP gene family was divided into five clades; apart from $H$. villosa, the other Triticeae species possessed genes in each of these clusters. In Triticeae species, the number of HIPPs increased in fold accordingly in different ploidy species-the diploids T. urartu, Ae. tauschii, and $H$. vulgare had 33, 40 and 33, respectively, while the tetraploid T. dicoccoides had 58 and the hexaploid T. aestivum had 114. Chromosome location analysis indicated that the HIPP genes were distributed on the chromosomes of each homologous group, while protein structure analysis showed that the structures of the HIPP proteins in the same clade were similar. This indicates that most HIPP genes were formed before the differentiation of Triticeae species. Only a few genes might have evolved independently after the differentiation of Triticeae species, or this result might be due to the lack of genomic sequence information.

\subsection{The HIPP Gene Family Might Regulate Plant Development and Various Responses to Stress in Common Wheat}

Roles of HIPP proteins in heavy-metal homeostasis and/or detoxification [23], cold- and salt-stress responses [28], virus long-distance movement [35], plant-pathogen interactions, and plant development [25] have been demonstrated. HIPP20, HIPP22, HIPP26, HIPP27, AtFP6, AtCdI9, and 
ATX1 from Arabidopsis and OsHIPP16, OsHIPP28, OsHIPP34, OsATX1, OsHIPP60, and OsHIPP29 from rice can positively regulate tolerance to heavy metals [22-24,26,30,32,53]. Different genes can be induced by different heavy metals, which, in turn, increase plant tolerance to different heavy metals. AtCdI9 can be induced by $\mathrm{Cd}, \mathrm{Hg}$, Fe, and $\mathrm{Cu}$ [30], while OsATX1 and OsHIPP60 can be induced by $\mathrm{Mn}, \mathrm{Cd}$, and $\mathrm{Cu}$ [26]. OsHIPP34-expressing yeast cells grow better in medium containing $60 \mu \mathrm{M} \mathrm{Cu}$, but show no difference in medium containing $\mathrm{Mn}, \mathrm{Cd}$, and $\mathrm{Zn}$ compared to the control. Meanwhile, OsHIPP60-expressing yeast cells grow better under $\mathrm{Cd}$ and $\mathrm{Zn}$ treatment, but show no difference under treatment with $\mathrm{Mn}$ and $\mathrm{Cu}$ compared to the control [26]. Some HIPP proteins can also bind to specific heavy metals: ATFP3 binds to transition-metal ions (e.g., $\mathrm{Cu}, \mathrm{Zn}$, and $\mathrm{Ni}$ ) in a reversible manner [51], HIPP3 from Arabidopsis can combine with Zn [25], and AtFP6 can combine with some divalent cations, such as $\mathrm{Pb}^{2+}, \mathrm{Cd}^{2+}$, and $\mathrm{Cu}^{2+}$. The expression profiles of $\mathrm{HvFP1}$ and HIPP26 are induced by cold and drought $[28,33]$. NbHIPP26 is expressed specifically in the vascular parenchyma and is induced by drought and PMTV (Potato Mop-Top Virus) infection-when NbHIPP26 is knocked down, the long-distance movement of the virus is suppressed [35]. HIPP3 acts as an upstream regulator of the salicylate-dependent pathway of pathogen response, and is also involved in abiotic-stress responses and seed and flower development [25]. Gene expression profiling analysis may provide important clues to gene functions. HIPP1- $V$ from $H$. villosa was upregulated under $C d$ treatment, and overexpression of HIPP1- $V$ indeed improved wheat tolerance to Cd stress. In this study, the HIPP genes showed different expression patterns in different tissues and different tolerances in wheat. TaHIPP16-B and TaHIPP7-B were highly expressed in the roots and were only upregulated in response to Bgt inoculation; TaHIPP24-D was highly expressed in the roots and was upregulated in response to $B g t$ inoculation and Pst infection; TaHIPP29-B was highly expressed in the spikes and was upregulated in response to drought and heat treatments. These results reveal the involvement of the different HIPPS in different biological processes; however, their specific roles need to be investigated by intensive functional analyses, such as the transgenic approach.

\subsection{Diversification of the Subcellular Localization Pattern of HIPP in H. villosa}

Protein localization and functions are related [54]. Isoprenylation, also known as farnesylation, is a post-translational protein modification that involves the addition of a C-terminal hydrophobic anchor, which is important for the interaction of a protein with membranes or other proteins $[23,55]$. All HIPP proteins contain an isoprenylation motif, which is then modified by isoprenylation. To the best of our knowledge, except for HIPP3 from Arabidopsis, all reported HIPP proteins localized on PM, including AtFP6 from Arabidopsis [22], NbHIPP26 from N. Benthamiana [35] and OsHIPP29 from rice [32]. Mutation in the isoprenylation domain may cause changes in protein localization; for instance, AtIPT3 farnesylation directs its localization in the nucleus/cytoplasm, whereas the nonfarnesylated protein is located in the plastids [56]. The wild-type CdI19 (GFP-CdI19W) is localized on the PM, whereas the farnesylated motif mutant CdI19 (in which the Cys-389 residue is replaced with Gly, GFPCdI19M) is localized in the entire cytoplasm, as is GFP [30]. Protein farnesylation of HIPPs has direct impacts on their function. For example, the function of AtNAP1;1 depends on its farnesylation motif-the wild-type AtNAP1;1 develops smaller leaves and cotyledons, while these organs are enlarged in plants expressing the mutant AtNAP1;1C369S (C369S transit at the CaaX motif) [57]. In our study, all HIPP proteins from $H$. villosa localized on PM, probably due their farnesylation, dependent on the CaaX motif. Most HMA-domain-containing proteins have heavy-metal-binding activity [23]; the membrane-associated characteristics of HIPPs-V may facilitate their binding affinities to specific heavy metals. Beside PM subcellular localization, several HIPPs-V also localized in other organelles, e.g., HIPP1/2/8/9/11-V had spot-like GFP signals in the cytoplasm; and except for HIPP2/5/9-V, all other HIPPs had nucleus GFP signals. Some HMA-domain-containing proteins participate in transporting heavy metals to maintain heavy-metal homeostasis [58]. HIPP1-V subcellularly localized both on PM and in cytoplasm. Its function in improving wheat tolerance to $\mathrm{Cd}$ may mediated by the binding and transportation of $\mathrm{Cd}$ for its homeostasis. NbHIPP26 is also subcellularly localized both on the 
plasma membrane and in the motile vesicles [35]. NbHIPP26, which plays roles in potato mop-top virus resistance, is related to the sensing and long-distance movement of viruses; it also regulates plant responses to drought stress [35]. The significance of the diverse subcellular localization of different HIPPs for their biological roles need to be further investigated.

\section{Materials and Methods}

\subsection{Plant Materials}

H. villosa (genome VV, accession no. 91C43) from the Cambridge Botanical Garden, Cambridge, U.K., was used for gene cloning and expression analysis. Commercial wheat variety Yangmai158, cultivated in the Institute of Agricultural Sciences in Lixiahe District of Jiangsu Province, was used as the transgenic receptor. $N$. benthamiana (NC89) plants were used for subcellular localization analysis. All plants were grown in a greenhouse and the growth conditions were as follows: $14 / 10 \mathrm{~h}$ day/night cycle, $24 / 20^{\circ} \mathrm{C}$ day/night temperature, and $70 \%$ relative humidity.

\subsection{Identification of the HIPP Gene Family in Triticeae Species}

The HIPP genes from Arabidopsis and Oryza were based on those previously identified [23] and download from the National Center for Biotechnology Information (NCBI, https://www.ncbi.nlm.nih. gov/). The "HMA protein" in the annotated proteins database of Hordeum vulgare (HH, $2 n=2 x=$ 14) [59] was searched and entries containing gene ID and protein sequences were obtained. We then performed a conserved-domains (CD) search (https://www.ncbi.nlm.nih.gov/Structure/cdd/wrpsb.cgi) and reserved the protein sequences that contained the HMA domain pfam00403.6 and the C-terminal isoprenylation motif CaaX. The presence of the isoprenylation motif, which was not characterized in the databases, was confirmed using PrePS [60].

The identified HIPP protein sequences of $H$. vulgare were used as query sequences to blast $(E$-value $\leq 10^{-10}$ ) against the protein databases of the other species, including T. urartu (AA, $2 n=2 x=14$ ) [61], T. aestivum (AABBDD, $2 n=6 x=42$ ) [62], B. distachyon (BdBd, $2 n=2 x=14$ ) [63], T. dicoccoides (AABB, $2 n=4 x=28$ ) [64], and Ae. tauschii (DD, $2 n=2 x=14$ ) [65]. After removing the redundant gene sequences for each species, the alignment hits were validated by performing a CD search and PrePS as described above.

\subsection{Cloning of HIPP Genes from Haynaldia villosa}

Prediction of HIPP in $H$. villosa was carried out by comparing the transcriptomic data of $H$. villosa (data unpublished) with the HIPP protein sequences of $H$. vulgare, and the predicted proteins were processed according to the above method. According to the sequences of the HIPP genes from $H$. vulgare, the primers (Supplementary Table S2) were designed to clone the full-length cDNA of the HIPP genes from H. villosa using online software Primer3 (v. 0.4.0, University of California, Oakland, CA, USA). Mixed root, stem, and leaf tissue cDNA of $H$. villosa served as a template for the isolation. The specific primers for the HIPP genes from $H$. villosa were used for cloning. This was performed at $95^{\circ} \mathrm{C}$ for $30 \mathrm{~s}$, followed by 32 cycles of $95{ }^{\circ} \mathrm{C}$ for $30 \mathrm{~s}, 56{ }^{\circ} \mathrm{C}$ for $45 \mathrm{~s}$, and $72{ }^{\circ} \mathrm{C}$ for $1 \mathrm{~min}$, and then 5 min at $72^{\circ} \mathrm{C}$ in Phanta Max Super-Fidelity DNA polymerase (Vazyme, Nanjing, China).

\subsection{Subcellular Localization}

Subcellular localization was performed as described by Zhao et al. [66] with the following modifications. The ORFs of the HIPP- $V$ genes (without stop codons) were cloned into vector pCambia1305-GFP to produce the fusion expression construct 1305-GFP: HIPP-V. The plasma membrane (PM) marker construct (mCherry-SYP122) was provided by Prof. Yiqun Bao. The 1305-GFP fusion constructs and mCherry-SYP122 were transformed into $N$. benthamiana epidermal cells by Agrobacterium tumefaciens (strain GV3101) bacteria, incubated in darkness at $22^{\circ} \mathrm{C}$ for $48-60 \mathrm{~h}$, and the fluorescence signals were then observed by confocal microscopy (LSM780, Zeiss, Oberkochen, Germany). 


\subsection{Phylogenetic Analysis of the HIPP Gene Family}

Phylogenetic analysis was performed as described by de Abreu-Neto et al. [23] with the following modifications. Multiple-sequence alignment was conducted using MUSCLE, which was integrated in MEGA X. The neighbor-joining analyses were performed in MEGA X using a p-distance parameter with 2000 bootstrap replications. Only the HMA domains were used to construct the phylogenetic tree.

\subsection{Chromosome Distribution and Protein Structure Analysis of the HIPP Gene Family}

Chromosomal information for the predicted HIPP genes from each species was obtained after using the cDNA sequences as a query sequence blasted to the genomic sequence to determine their chromosomal locations. Their locations were then drawn onto the physical map of each chromosome using Tbtools [67].

The domains of the wheat HIPP proteins were predicted using a CD search (https://www.ncbi.nlm. nih.gov/Structure/cdd/wrpsb.cgi). The corresponding evolutionary trees were constructed by MEGA X as described above. The formation of the protein structure was constructed using Tbtools [67].

\subsection{RNA-seq Expression Analysis}

The expression data were downloaded from expVIP to analyze the expression pattern of predicted wheat HIPP genes in different tissues (e.g., roots, leaves, spikes, and grains) under abiotic stress (e.g., drought and heat), and biotic stress (e.g., stripe rust and powdery mildew) [68], and the Z-score-normalized values of the TPM were used to construct the expression heat map using $R$ version 3.5.1.

\subsection{Transcription Abundance Analysis}

H. villosa plants were grown in liquid Murashige and Skoog (MS) medium at $22-25^{\circ} \mathrm{C}$ with a photoperiod of $12 \mathrm{~h}$ until the third-leaf stage. For expression analysis in response to $\mathrm{Cd}$ treatment, plants were inoculated with $1 \mathrm{mM} \mathrm{CdCl}_{2}$ and the leaves, stems, and roots were collected at $0,1,2,6,12$, or $24 \mathrm{~h}$ after treatment. All of the samples were rapidly frozen in liquid nitrogen, then stored in an ultrafreezer $\left(-80^{\circ} \mathrm{C}\right)$ until use.

Total RNA was extracted using TRIZOL reagent according to the manufacturer's protocol (Invitrogen, Carlsbad, CA, USA), and the sample was used to synthesize the first-strand cDNA using an RNA PCR Kit (TaKaRa, Shiga, Japan). Specific primers for HIPP1-V were used for qRT-PCR (Supplementary Table S2), and the tubulin gene was used as the internal control for normalization. qRT-PCR was performed with AceQ SYBR Green (Vazyme, Nanjing, China) using a Louts PCR 480 sequence detection system. The reactions were subjected to the following program: $95^{\circ} \mathrm{C}$ for $1 \mathrm{~min}$, 41 cycles of $95^{\circ} \mathrm{C}$ for $10 \mathrm{~s}$, and $60^{\circ} \mathrm{C}$ for $30 \mathrm{~s}$. The relative values of gene expression were derived from $2^{-\Delta \Delta C T}[69]$.

\subsection{Genetic Transformation}

HIPP1- $V$ was cloned into the plant expression vector pBI220 (driven by the CAMV 35S promoter) to generate vectors $\mathrm{pBI} 220$ : HIPP1-V. The method of stable transformation using bombardment was applied according to Xing et al. [70]. The vector pBI220: HIPP1-V, together with pAHC20 (carrying the Bar gene as a selectable marker), was co-transformed by bombardment into calli produced from young embryos of wheat cultivar Yangmai158. Regenerated plants were transplanted in the field and used for further characterization. Regenerated plants were analyzed via PCR using conjugated gene-specific primers CAMV35S-F and HIPP1-V-R (Supplementary Table S2) to identify positive transgenic plants.

\subsection{Cd-Tolerance Analysis}

For the Cd-tolerance tests, seeds of HIPP1- $V$ transgenic plants and the receptor variety Yangmai158 were sterilized with $75 \%$ ethanol and $12 \% \mathrm{NaClO}$ and washed five times with sterile water. To determine 
plant height and root length, the seeds were grown on 1/2 liquid Murashige and Skoog medium containing different concentrations of $\mathrm{CdCl}_{2}$ (e.g., 0, 5, 10, 20, 50, 100, 200, 500, 1000, 5000, 10,000 and $20,000 \mu \mathrm{M}$ ) for 15 days. The growth conditions were as follows: $14 / 10 \mathrm{~h}$ day/night cycle, $24 / 20^{\circ} \mathrm{C}$ day/night temperature, and $70 \%$ relative humidity. The plant height and root length were measured and analyzed. The plant height and root length averages were computed based on the means of three independent experiments, each based on at least 10 independent plants, and the significance analysis was performed using Excel software.

\section{Conclusions}

The present study identified 278 HIPP genes from five Triticeae species and cloned 13 HIPP genes from $H$. villosa. Evolutionary and protein structure analyses showed that the HIPP genes are conserved in Triticeae species. The expression analysis of the HIPP gene family in common wheat and subcellular localization analysis of HIPPs-V showed that the functions of the HIPP genes may be involved in multiple pathways of plant development. HIPP1- $V$ was upregulated in the roots, stems, and leaves of $H$. villosa in response to Cd treatment, and overexpression of HIPP1-V enhanced the tolerance of common wheat to $\mathrm{Cd}$. Our study systematically analyzed the function and evolution of the HIPP gene family in Triticeae species and demonstrated the important role of HIPP1-V in heavy-metal homeostasis and detoxification.

Supplementary Materials: The following are available online at http://www.mdpi.com/1422-0067/21/17/6191/s1, Figure S1. Phylogenetic analysis and protein structures of the heavy-metal-associated isoprenylated plant protein (HIPP) gene family in common wheat and related Triticeae species. Figure S2. Venn diagrams of differentially expressed HIPPs under different stresses. Figure S3. Identification of positive transgenic plants for HIPP1-V. Table S1. Features of the HIPP genes identified in Triticum urartu, Aegilops tauschii, Triticum dicoccoides, Triticum aestivum, Hordeum vulgare, and Brachypodium distachyon. Table S2. Primers used in this study.

Author Contributions: Data curation, H.Z., X.Z., Y.H., L.S. and J.X.; formal analysis, H.Z., J.L., Y.N., Y.C., J.Z. and H.W.; funding acquisition, J.X. and X.W.; methodology, H.Z., X.Z., Y.N. and H.W.; project administration, X.W.; validation, J.L., Y.N., Y.C. and L.S.; visualization, H.Z., X.Z., J.Z. and J.X.; writing-original draft, H.Z. and Y.C.; writing-review and editing, J.X. and X.W. All authors have read and agreed to the published version of the manuscript.

Funding: This research was supported by grants from the National Key Research and Development Program (No. 2016YFD0101004 and 2016YFD0102001-004), the National Natural Science Foundation of China (Major Program) (No. 91935304), the International Cooperation and Exchange of the National Natural Science Foundation of China (No. 31661143005), the National Natural Science Foundation of China (No. 31971943), the special fund of Jiangsu Province for the transformation of scientific and technological achievements (No. BA2017138), the Program of Introducing Talents of Discipline to Universities (No. B08025), the Creation of Major New Agricultural Varieties in Jiangsu Province (No. PZCZ201706), the Jiangsu Agricultural Technology System (JATS) (No. JATS [2019] 429), and the Key Research and Development Major Project of Ningxia Autonomous Region (No. 2019BBF02022-04).

Conflicts of Interest: The authors declare no conflict of interest.

\section{Abbreviations}

$\begin{array}{ll}\text { GFP } & \text { Green Fluorescent Protein } \\ \text { CDS } & \text { Coding Sequence } \\ \text { aa } & \text { Amino Acid } \\ \text { qRT-PCR } & \text { Quantitative Reverse Transcription PCR } \\ \text { ORF } & \text { Open Reading Frame }\end{array}$

\section{References}

1. Eapen, S.; D'Souza, S.F. Prospects of genetic engineering of plants for phytoremediation of toxic metals. Biotechnol. Adv. 2005, 23, 97-114. [CrossRef] [PubMed]

2. Miransari, M. Hyperaccumulators, arbuscular mycorrhizal fungi and stress of heavy metals. Biotechnol. Adv. 2011, 29, 645-653. [CrossRef] [PubMed]

3. Fang, W.; Wu, P. Elevated selenium and other mineral element concentrations in soil and plant tissue in bone coal sites in Haoping area, Ziyang County, China. Plant Soil 2004, 261, 135-146. [CrossRef] 
4. Macnair, M.R. The genetics of metal tolerance in vascular plants. New Phytol. 1993, 124, 541-559. [CrossRef]

5. Garzon, T.; Gunse, B.; Moreno, A.R.; Tomos, A.D.; Barcelo, J.; Poschenrieder, C. Aluminium-induced alteration of ion homeostasis in root tip vacuoles of two maize varieties differing in Al tolerance. Plant Sci. Int. J. Exp. Plant Biol. 2011, 180, 709-715. [CrossRef]

6. Hayat, S.; Khalique, G.; Irfan, M.; Wani, A.S.; Tripathi, B.N.; Ahmad, A. Physiological changes induced by chromium stress in plants: An overview. Protoplasma 2012, 249, 599-611. [CrossRef]

7. Shahid, M.; Pinelli, E.; Dumat, C. Review of Pb availability and toxicity to plants in relation with metal speciation; role of synthetic and natural organic ligands. J. Hazard. Mater. 2012, 219-220, 1-12. [CrossRef]

8. Gill, S.S.; Hasanuzzaman, M.; Nahar, K.; Macovei, A.; Tuteja, N. Importance of nitric oxide in cadmium stress tolerance in crop plants. Plant Physiol. Biochem. 2013, 63, 254-261. [CrossRef]

9. Singh, S.; Parihar, P.; Singh, R.; Singh, V.P.; Prasad, S.M. Heavy Metal Tolerance in Plants: Role of Transcriptomics, Proteomics, Metabolomics, and Ionomics. Front. Plant Sci. 2015, 6, 1143. [CrossRef]

10. Morel, F.M. The co-evolution of phytoplankton and trace element cycles in the oceans. Geobiology 2008, 6, 318-324. [CrossRef]

11. Chen, F.; Wang, F.; Wu, F.; Mao, W.; Zhang, G.; Zhou, M. Modulation of exogenous glutathione in antioxidant defense system against $\mathrm{Cd}$ stress in the two barley genotypes differing in Cd tolerance. Plant Physiol. Biochem. 2010, 48, 663-672. [CrossRef]

12. Yu, C.; Sun, C.; Shen, C.; Wang, S.; Liu, F.; Liu, Y.; Chen, Y.; Li, C.; Qian, Q.; Aryal, B.; et al. The auxin transporter, OsAUX1, is involved in primary root and root hair elongation and in Cd stress responses in rice (Oryza sativa L.). Plant J. Cell Mol. Biol. 2015, 83, 818-830. [CrossRef]

13. Rizwan, M.; Meunier, J.D.; Davidian, J.C.; Pokrovsky, O.S.; Bovet, N.; Keller, C. Silicon alleviates Cd stress of wheat seedlings (Triticum turgidum L. cv. Claudio) grown in hydroponics. Environ. Sci. Pollut. Res. Int. 2016, 23, 1414-1427. [CrossRef]

14. Dong, J.; Wu, F.B.; Zhang, G.P. Effect of cadmium on growth and photosynthesis of tomato seedlings. J. Zhejiang Univ. Sci. B 2005, 6, 974-980. [CrossRef]

15. Martinoia, E.; Klein, M.; Geisler, M.; Bovet, L.; Forestier, C.; Kolukisaoglu, U.; Muller-Rober, B.; Schulz, B. Multifunctionality of plant ABC transporters-more than just detoxifiers. Planta 2002, 214, 345-355. [CrossRef]

16. Lin, Y.F.; Liang, H.M.; Yang, S.Y.; Boch, A.; Clemens, S.; Chen, C.C.; Wu, J.F.; Huang, J.L.; Yeh, K.C. Arabidopsis IRT3 is a zinc-regulated and plasma membrane localized zinc/iron transporter. New Phytol. 2009, 182, 392-404. [CrossRef]

17. Filatov, V.; Dowdle, J.; Smirnoff, N.; Ford-Lloyd, B.; Newbury, H.J.; Macnair, M.R. Comparison of gene expression in segregating families identifies genes and genomic regions involved in a novel adaptation, zinc hyperaccumulation. Mol. Ecol. 2006, 15, 3045-3059. [CrossRef]

18. Lei, G.J.; Fujii-Kashino, M.; Wu, D.Z.; Hisano, H.; Saisho, D.; Deng, F.; Yamaji, N.; Sato, K.; Zhao, F.-J.; Ma, J.F. Breeding for low cadmium barley by introgression of a Sukkula-like transposable element. Nat. Food 2020, 1, 489-499. [CrossRef]

19. Zhang, L.; Gao, C.; Chen, C.; Zhang, W.; Huang, X.-Y.; Zhao, F.-J. Overexpression of Rice OsHMA3 in Wheat Greatly Decreases Cadmium Accumulation in Wheat Grains. Environ. Sci. Technol. 2020. [CrossRef]

20. Gustin, J.L.; Loureiro, M.E.; Kim, D.; Na, G.; Tikhonova, M.; Salt, D.E. MTP1-dependent Zn sequestration into shoot vacuoles suggests dual roles in $\mathrm{Zn}$ tolerance and accumulation in Zn-hyperaccumulating plants. Plant J. Cell Mol. Biol. 2009, 57, 1116-1127. [CrossRef]

21. Lanquar, V.; Lelievre, F.; Bolte, S.; Hames, C.; Alcon, C.; Neumann, D.; Vansuyt, G.; Curie, C.; Schroder, A.; Kramer, U.; et al. Mobilization of vacuolar iron by AtNRAMP3 and AtNRAMP4 is essential for seed germination on low iron. EMBO J. 2005, 24, 4041-4051. [CrossRef]

22. Gao, W.; Xiao, S.; Li, H.Y.; Tsao, S.W.; Chye, M.L. Arabidopsis thaliana acyl-CoA-binding protein ACBP2 interacts with heavy-metal-binding farnesylated protein AtFP6. New Phytol. 2009, 181, 89-102. [CrossRef]

23. de Abreu-Neto, J.B.; Turchetto-Zolet, A.C.; de Oliveira, L.F.; Zanettini, M.H.; Margis-Pinheiro, M. Heavy metal-associated isoprenylated plant protein (HIPP): Characterization of a family of proteins exclusive to plants. FEBS J. 2013, 280, 1604-1616. [CrossRef]

24. Tehseen, M.; Cairns, N.; Sherson, S.; Cobbett, C.S. Metallochaperone-like genes in Arabidopsis thaliana. Metallomics 2010, 2, 556-564. [CrossRef] 
25. Zschiesche, W.; Barth, O.; Daniel, K.; Bohme, S.; Rausche, J.; Humbeck, K. The zinc-binding nuclear protein HIPP3 acts as an upstream regulator of the salicylate-dependent plant immunity pathway and of flowering time in Arabidopsis thaliana. New Phytol. 2015, 207, 1084-1096. [CrossRef]

26. Khan, I.U.; Rono, J.K.; Zhang, B.Q.; Liu, X.S.; Wang, M.Q.; Wang, L.L.; Wu, X.C.; Chen, X.; Cao, H.W.; Yang, Z.M. Identification of novel rice (Oryza sativa) HPP and HIPP genes tolerant to heavy metal toxicity. Ecotoxicol. Environ. Saf. 2019, 175, 8-18. [CrossRef]

27. Manara, A.; Fasani, E.; Molesini, B.; DalCorso, G.; Pennisi, F.; Pandolfini, T.; Furini, A. The Tomato Metallocarboxypeptidase Inhibitor I, which Interacts with a Heavy Metal-Associated Isoprenylated Protein, Is Implicated in Plant Response to Cadmium. Molecules 2020, 25. [CrossRef]

28. Barth, O.; Zschiesche, W.; Siersleben, S.; Humbeck, K. Isolation of a novel barley cDNA encoding a nuclear protein involved in stress response and leaf senescence. Physiol. Plant. 2004, 121, 282-293. [CrossRef]

29. Zhang, X.; Feng, H.; Feng, C.; Xu, H.; Huang, X.; Wang, Q.; Duan, X.; Wang, X.; Wei, G.; Huang, L.; et al. Isolation and characterisation of cDNA encoding a wheat heavy metal-associated isoprenylated protein involved in stress responses. Plant Biol. 2015, 17, 1176-1186. [CrossRef]

30. Suzuki, N.; Yamaguchi, Y.; Koizumi, N.; Sano, H. Functional characterization of a heavy metal binding protein CdI19 from Arabidopsis. Plant J. Cell Mol. Biol. 2002, 32, 165-173. [CrossRef]

31. Zhang, P.; Wang, R.; Ju, Q.; Li, W.; Tran, L.P.; Xu, J. The R2R3-MYB Transcription Factor MYB49 Regulates Cadmium Accumulation. Plant Physiol. 2019, 180, 529-542. [CrossRef]

32. Zhang, B.Q.; Liu, X.S.; Feng, S.J.; Zhao, Y.N.; Wang, L.L.; Rono, J.K.; Li, H.; Yang, Z.M. Developing a cadmium resistant rice genotype with OsHIPP29 locus for limiting cadmium accumulation in the paddy crop. Chemosphere 2020, 247, 125958. [CrossRef]

33. Barth, O.; Vogt, S.; Uhlemann, R.; Zschiesche, W.; Humbeck, K. Stress induced and nuclear localized HIPP26 from Arabidopsis thaliana interacts via its heavy metal associated domain with the drought stress related zinc finger transcription factor ATHB29. Plant Mol. Biol. 2009, 69, 213-226. [CrossRef]

34. Radakovic, Z.S.; Anjam, M.S.; Escobar, E.; Chopra, D.; Cabrera, J.; Silva, A.C.; Escobar, C.; Sobczak, M.; Grundler, F.M.W.; Siddique, S. Arabidopsis HIPP27 is a host susceptibility gene for the beet cyst nematode Heterodera schachtii. Mol. Plant Pathol. 2018. [CrossRef]

35. Cowan, G.H.; Roberts, A.G.; Jones, S.; Kumar, P.; Kalyandurg, P.B.; Gil, J.F.; Savenkov, E.I.; Hemsley, P.A.; Torrance, L. Potato Mop-Top Virus Co-Opts the Stress Sensor HIPP26 for Long-Distance Movement. Plant Physiol. 2018, 176, 2052-2070. [CrossRef]

36. Liu, J.L.; Zhang, D.X.; Hong, L. Isolation, characterization and functional annotation of the salt tolerance genes through screening the high-quality cDNA library of the halophytic green alga Dunaliella salina (Chlorophyta). Ann. Microbiol. 2015, 65, 1293-1302. [CrossRef]

37. Wang, Y.; Liu, H.; Wang, S.; Li, H.; Xin, Q. Overexpression of a Common Wheat Gene GALACTINOL SYNTHASE3 Enhances Tolerance to Zinc in Arabidopsis and Rice Through the Modulation of Reactive Oxygen Species Production. Plant Mol. Biol. Rep. 2016, 34, 794-806. [CrossRef]

38. Khoudi, H.; Maatar, Y.; Gouiaa, S.; Masmoudi, K. Transgenic tobacco plants expressing ectopically wheat $\mathrm{H}(+)$-pyrophosphatase (H(+)-PPase) gene TaVP1 show enhanced accumulation and tolerance to cadmium. J. Plant Physiol. 2012, 169, 98-103. [CrossRef]

39. Ren, Y.; Chen, Y.; An, J.; Zhao, Z.; Zhang, G.; Wang, Y.; Wang, W. Wheat expansin gene TaEXPA2 is involved in conferring plant tolerance to Cd toxicity. Plant Sci. Int. J. Exp. Plant Biol. 2018, 270, 245-256. [CrossRef]

40. Qiao, K.; Gong, L.; Tian, Y.; Wang, H.; Chai, T. The metal-binding domain of wheat heavy metal ATPase 2 (TaHMA2) is involved in zinc/cadmium tolerance and translocation in Arabidopsis. Plant Cell Rep. 2018, 37, 1343-1352. [CrossRef]

41. Wang, F.; Wang, Z.; Zhu, C. Heteroexpression of the wheat phytochelatin synthase gene (TaPCS1) in rice enhances cadmium sensitivity. Acta Biochim. Biophys. Sin. 2012, 44, 886-893. [CrossRef]

42. Qiao, K.; Wang, F.; Liang, S.; Wang, H.; Hu, Z.; Chai, T. Improved Cd, Zn and Mn tolerance and reduced Cd accumulation in grains with wheat-based cell number regulator TaCNR2. Sci. Rep. 2019, 9, 870. [CrossRef]

43. Clemens, S.; Kim, E.J.; Neumann, D.; Schroeder, J.I. Tolerance to toxic metals by a gene family of phytochelatin synthases from plants and yeast. EMBO J. 1999, 18, 3325-3333. [CrossRef]

44. Sun, H.; Song, J.; Lei, J.; Song, X.; Dai, K.; Xiao, J.; Yuan, C.; An, S.; Wang, H.; Wang, X. Construction and application of oligo-based FISH karyotype of Haynaldia villosa. J. Genet. Genom. Yi Chuan Xue Bao 2018, 45, 463-466. [CrossRef] 
45. Cao, A.; Xing, L.; Wang, X.; Yang, X.; Wang, W.; Sun, Y.; Qian, C.; Ni, J.; Chen, Y.; Liu, D.; et al. Serine/threonine kinase gene $S t p k-V$, a key member of powdery mildew resistance gene Pm21, confers powdery mildew resistance in wheat. Proc. Natl. Acad. Sci. USA 2011, 108, 7727-7732. [CrossRef]

46. Zhu, Y.; Li, Y.; Fei, F.; Wang, Z.; Wang, W.; Cao, A.; Liu, Y.; Han, S.; Xing, L.; Wang, H.; et al. E3 ubiquitin ligase gene CMPG1-V from Haynaldia villosa L. contributes to powdery mildew resistance in common wheat (Triticum aestivum L.). Plant J. Cell Mol. Biol. 2015, 84, 154-168. [CrossRef]

47. Zhang, Z.W.; Moon, C.S.; Watanabe, T.; Shimbo, S.; Ikeda, M. Contents of pollutant and nutrient elements in rice and wheat grown on the neighboring fields. Biol. Trace Elem. Res. 1997, 57, 39-50. [CrossRef]

48. Zhang, Y.; Chen, K.; Zhao, F.J.; Sun, C.; Jin, C.; Shi, Y.; Sun, Y.; Li, Y.; Yang, M.; Jing, X.; et al. OsATX1 Interacts with Heavy Metal P1B-Type ATPases and Affects Copper Transport and Distribution. Plant Physiol. 2018, 178, 329-344. [CrossRef]

49. Tan, J.; Wang, J.; Chai, T.; Zhang, Y.; Feng, S.; Li, Y.; Zhao, H.; Liu, H.; Chai, X. Functional analyses of TaHMA2, a P(1B)-type ATPase in wheat. Plant Biotechnol. J. 2013, 11, 420-431. [CrossRef]

50. Ci, D.; Jiang, D.; Wollenweber, B.; Dai, T.; Jing, Q.; Cao, W. Genetic Variance in Cadmium Tolerance and Accumulation in Wheat Materials Differing in Ploidy and Genome at Seedling Stage. J. Agron. Crop Sci. 2010, 196, 302-310. [CrossRef]

51. Dykema, P.E.; Sipes, P.R.; Marie, A.; Biermann, B.J.; Crowell, D.N.; Randall, S.K. A new class of proteins capable of binding transition metals. Plant Mol. Biol. 1999, 41, 139-150. [CrossRef]

52. Lynch, M.; Conery, J.S. The evolutionary fate and consequences of duplicate genes. Science 2000, 290, 1151-1155. [CrossRef]

53. Himelblau, E.; Mira, H.; Lin, S.J.; Culotta, V.C.; Penarrubia, L.; Amasino, R.M. Identification of a functional homolog of the yeast copper homeostasis gene ATX1 from Arabidopsis. Plant Physiol. 1998, 117, 1227-1234. [CrossRef] [PubMed]

54. Feng, S.J.; Liu, X.S.; Ma, L.Y.; Khan, I.U.; Rono, J.K.; Yang, Z.M. Identification of epigenetic mechanisms in paddy crop associated with lowering environmentally related cadmium risks to food safety. Environ. Pollut. 2020, 256, 113464. [CrossRef] [PubMed]

55. Novelli, G.; D’Apice, M.R. Protein farnesylation and disease. J. Inherit. Metab. Dis. 2012, 35, 917-926. [CrossRef] [PubMed]

56. Galichet, A.; Hoyerova, K.; Kaminek, M.; Gruissem, W. Farnesylation directs AtIPT3 subcellular localization and modulates cytokinin biosynthesis in Arabidopsis. Plant Physiol. 2008, 146, 1155-1164. [CrossRef] [PubMed]

57. Galichet, A.; Gruissem, W. Developmentally controlled farnesylation modulates AtNAP1;1 function in cell proliferation and cell expansion during Arabidopsis leaf development. Plant Physiol. 2006, 142, 1412-1426. [CrossRef]

58. Chu, C.C.; Lee, W.C.; Guo, W.Y.; Pan, S.M.; Chen, L.J.; Li, H.M.; Jinn, T.L. A copper chaperone for superoxide dismutase that confers three types of copper/zinc superoxide dismutase activity in Arabidopsis. Plant Physiol. 2005, 139, 425-436. [CrossRef]

59. Mascher, M.; Gundlach, H.; Himmelbach, A.; Beier, S.; Twardziok, S.O.; Wicker, T.; Radchuk, V.; Dockter, C.; Hedley, P.E.; Russell, J.; et al. A chromosome conformation capture ordered sequence of the barley genome. Nature 2017, 544, 427-433. [CrossRef]

60. Maurer-Stroh, S.; Eisenhaber, F. Refinement and prediction of protein prenylation motifs. Genome Biol. 2005, 6, R55. [CrossRef]

61. Ling, H.Q.; Ma, B.; Shi, X.; Liu, H.; Dong, L.; Sun, H.; Cao, Y.; Gao, Q.; Zheng, S.; Li, Y.; et al. Genome sequence of the progenitor of wheat A subgenome Triticum Urartu. Nature 2018, 557, 424-428. [CrossRef] [PubMed]

62. International Wheat Genome Sequencing Consortium. A chromosome-based draft sequence of the hexaploid bread wheat (Triticum aestivum) genome. Science 2014, 345, 1251788. [CrossRef]

63. International Brachypodium Initiative. Genome sequencing and analysis of the model grass Brachypodium distachyon. Nature 2010, 463, 763-768. [CrossRef]

64. Avni, R.; Nave, M.; Barad, O.; Baruch, K.; Twardziok, S.O.; Gundlach, H.; Hale, I.; Mascher, M.; Spannagl, M.; Wiebe, K.; et al. Wild emmer genome architecture and diversity elucidate wheat evolution and domestication. Science 2017, 357, 93-97. [CrossRef] [PubMed] 
65. Luo, M.C.; Gu, Y.Q.; Puiu, D.; Wang, H.; Twardziok, S.O.; Deal, K.R.; Huo, N.; Zhu, T.; Wang, L.; Wang, Y.; et al. Genome sequence of the progenitor of the wheat D genome Aegilops tauschii. Nature 2017, 551, 498-502. [CrossRef]

66. Zhao, J.; Zhang, X.; Wan, W.; Zhang, H.; Liu, J.; Li, M.; Wang, H.; Xiao, J.; Wang, X. Identification and Characterization of the EXO70 Gene Family in Polyploid Wheat and Related Species. Int. J. Mol. Sci. 2018, 20. [CrossRef] [PubMed]

67. Chen, C.; Xia, R.; Chen, H.; He, Y. TBtools, a Toolkit for Biologists integrating various HTS-data handling tools with a user-friendly interface. BioRxiv 2018, 289660. [CrossRef]

68. Borrill, P.; Ramirez-Gonzalez, R.; Uauy, C. expVIP: A Customizable RNA-seq Data Analysis and Visualization Platform. Plant Physiol. 2016, 170, 2172-2186. [CrossRef]

69. Livak, K.J.; Schmittgen, T.D. Analysis of relative gene expression data using real-time quantitative PCR and the $2^{-\Delta \Delta C T}$ method. Methods 2001, 25, 402-408. [CrossRef]

70. Xing, L.P.; Wang, H.Z.; Jiang, Z.N.; Ni, J.L.; Cao, A.Z.; Yu, L.; Chen, P.D. Transformation of Wheat Thaumatin-Like Protein Gene and Analysis of Reactions to Powdery Mildew and Fusarium Head Blight in Transgenic Plants. Acta Agron. Sin. 2008, 34, 349-354. [CrossRef]

(C) 2020 by the authors. Licensee MDPI, Basel, Switzerland. This article is an open access article distributed under the terms and conditions of the Creative Commons Attribution (CC BY) license (http://creativecommons.org/licenses/by/4.0/). 